\title{
Glyoxal vertical columns from GOME-2 backscattered light measurements and comparisons with a global model
}

\author{
C. Lerot, T. Stavrakou, I. De Smedt, J.-F. Müller, and M. Van Roozendael \\ Belgian Institute for Space Aeronomy (BIRA-IASB), Brussels, Belgium \\ Received: 7 July 2010 - Published in Atmos. Chem. Phys. Discuss.: 6 September 2010 \\ Revised: 3 December 2010 - Accepted: 7 December 2010 - Published: 17 December 2010
}

\begin{abstract}
Glyoxal vertical column densities have been retrieved from nadir backscattered radiances measured from 2007 to 2009 by the spaceborne GOME-2/METOP-A sensor. The retrieval algorithm is based on the DOAS technique and optimized settings have been used to determine glyoxal slant columns. The liquid water absorption is accounted for using a two-step DOAS approach, leading to a drastic improvement of the fit quality over remote clear water oceans. Air mass factors are calculated by means of look-up tables of weighting functions pre-calculated with the LIDORT v3.3 radiative transfer model and using a priori glyoxal vertical distributions provided by the IMAGESv2 chemical transport model. The total error estimate comprises random and systematic errors associated to the DOAS fit, the air mass factor calculation and the cloud correction. The highest glyoxal vertical column densities are mainly observed in continental tropical regions, while the mid-latitude columns strongly depend on the season with maximum values during warm months. An anthropogenic signature is also observed in highly populated regions of Asia. Comparisons with glyoxal columns simulated with IMAGESv2 in different regions of the world generally point to a missing glyoxal source, most probably of biogenic origin.
\end{abstract}

\section{Introduction}

Glyoxal (CHOCHO) has been recently the subject of a growing number of literature studies. Global chemistry transport models based on current inventories and chemical mechanisms estimate the global glyoxal source at $45-56 \mathrm{Tg} / \mathrm{yr}$ (Fu et al., 2008; Myriokefalitakis et al., 2008; Stavrakou et al., 2009b). The major part of this source is due to the

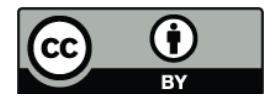

Correspondence to: C. Lerot (christophe.lerot@aeronomie.be) oxidation of NMVOCs (non-methane volatile organic compounds) emitted naturally (55\%) and by human activities $(21 \%)$, whereas direct glyoxal emissions (vegetation fires, fossil fuel and biofuel combustion) contribute also to the global source (16\%, Stavrakou et al., 2009b). About half of the glyoxal sink is due to photolysis, whereas oxidation by $\mathrm{OH}$, and dry and wet deposition account for the remainder. Its short lifetime (2.5-3 h globally) makes glyoxal a good indicator for reactive NMVOC chemistry.

However, discrepancies arise when comparing model results with the space-based glyoxal column data set from the SCIAMACHY instrument (Wittrock et al., 2006; Vrekoussis et al., 2009). It turns out that models generally underpredict the observed glyoxal columns over both continental and oceanic regions. The disagreement is attributed to the existence of a missing source, and/or an overestimated sink (Myriokefalitakis et al., 2008). An inverse modelling study constrained by glyoxal columns retrieved from SCIAMACHY suggests that, in order to reach a good agreement with the observations, the global continental glyoxal source should be twice as large as the a priori value, $108 \mathrm{Tg} / \mathrm{yr}$ instead of $56 \mathrm{Tg} / \mathrm{yr}$ (Stavrakou et al., 2009b). Although half of this source can be understood in terms of identified sources, the formation mechanisms for the remaining production are unknown by now.

Equally interesting, unexpectedly high glyoxal columns measured by SCIAMACHY over the tropical oceans suggest the existence of a potentially important oceanic source of glyoxal, estimated at about $20 \mathrm{Tg} / \mathrm{yr}$ based on beforehand calculations (Myriokefalitakis et al., 2008). Such elevated oceanic glyoxal columns are corroborated by the first shipbased measurements in the marine boundary layer of the remote tropical Pacific (Volkamer et al., 2010; Sinreich et al., 2010) also reporting very high glyoxal mixing ratios (up to $140 \mathrm{pptv}$ ), for which no convincing interpretation is available at this moment.

Published by Copernicus Publications on behalf of the European Geosciences Union. 
Further interest in glyoxal originates from its recognized potential for formation of secondary organic aerosols (SOA, Fu et al. (2008), Stavrakou et al. (2009b), Ervens and Volkamer (2010) and references therein). Glyoxal is expected to be one of the missing links necessary to bridge the gap between observed and modelled organic carbon concentrations. Although there exists experimental evidence for SOA production from glyoxal processing in clouds and fog (modelling studies estimate this production to range between 5.5 and $10 \mathrm{Tg} / \mathrm{yr}$ ), the SOA formation in aqueous aerosol particles is not completely understood and persistent uncertainties still remain.

Glyoxal is characterized by absorption bands in the visible region (400-460 nm), making its detection possible using the Differential Optical Absorption Spectroscopy (DOAS) technique (Platt and Stutz, 2008), as primarily demonstrated by Volkamer et al. (2005b). However, such measurements remain challenging, especially from spaceborne instruments, due to the overall faintness of the $\mathrm{CHOCHO}$ signal. The first SCIAMACHY glyoxal vertical column retrievals (Wittrock et al., 2006) are limited by the fact that the global coverage of this instrument is only reached in six days as the satellite alternates between the nadir- and limb-viewing geometries, respectively used for column and stratospheric profile measurements. In this paper, we focus on glyoxal measurements retrieved from nadir observations of the GOME-2 instrument aboard the Metop-A platform. GOME-2 measures the sunlight backscattered by the Earth's atmosphere between 240 $\mathrm{nm}$ and $790 \mathrm{~nm}$ since October 2006 (Munro et al., 2006). It is characterized by a ground resolution of $80 \mathrm{~km} \times 40 \mathrm{~km}$, and is able to deliver a global coverage in 1.5 day. With a higher number of daily observations compared to SCIAMACHY, GOME-2 is expected to better resolve the spatial structures of the glyoxal abundances, therefore allowing for a better identification of the emissions. We present here glyoxal column data retrieved between January 2007 and December 2009.

In Sect. 2, the algorithm used to retrieve the glyoxal vertical columns from the GOME-2 spectra is described. Particular focus is put on algorithm improvements over oceanic scenes through the inclusion of the liquid water absorption in the DOAS retrievals (Sect. 2.1.2). A comprehensive error budget is presented in Sect. 3. The IMAGESv2 global chemistry transport model, briefly described in Sect. 4, is used to compare the model predictions with the observed vertical columns. We present and discuss global distributions and time series over selected large regions worldwide in Sect. 5 . Conclusions are drawn in Sect. 6.

\section{Algorithm description}

The glyoxal vertical column retrievals from the GOME-2 spectra are based on the DOAS technique (Platt and Stutz, 2008), which implies a two step procedure. First, a slant column density SCD, i.e. the concentration integrated along the mean photon path, is retrieved using the structured absorption bands of the species under study. Second, the SCD is converted into a vertical column using air mass factors calculated with a radiative transfer model.

\subsection{Slant column density retrieval}

The absorption bands of glyoxal are structured enough to allow the retrieval of glyoxal SCDs using the DOAS technique. All broadband effects, such as molecular scattering, aerosol scattering and reflection from the Earth's surface, are filtered out by fitting through the measured transmittance (ratio of earthshine radiance and solar irradiance) a low-order polynomial. The remaining high-frequency spectral features originate from the absorption of trace gases present in the atmosphere, and also from the rotational Raman scattering (Ring effect; Grainger and Ring, 1962). The DOAS retrieval consists in minimizing the least squares difference between the differential optical densities measured by the instrument and those calculated using scaled reference spectra. The parameters adjusted in this procedure are the slant column densities.

\subsubsection{Retrieval settings}

The selected fitting window $(435-460 \mathrm{~nm})$ includes the two strongest glyoxal absorption bands. Intense interferences between the glyoxal and Ring spectral features below $430 \mathrm{~nm}$ prevent the extension of the window towards the ultraviolet (Vrekoussis et al., 2009). The reference glyoxal absorption cross-sections used in the retrievals have been measured by Volkamer et al. (2005a) at high resolution. In this spectral region, the absorption of light by ozone, $\mathrm{NO}_{2}$, water vapour and the $\mathrm{O}_{2}-\mathrm{O}_{2}$ collision pair is significant and is considered by including their respective reference absorption crosssection in the DOAS retrievals. All reference cross-section data sets, listed in Table 1, have been degraded at the GOME2 resolution using the slit function data measured by Siddans et al. (2006). The Ring effect is treated as a pseudo-absorber for which a reference spectrum, calculated as in Chance and Spurr (1997), is also included in the fit. Furthermore, interferences with the liquid water absorption spectrum lead to strongly negative glyoxal SCD over clear water oceanic regions if not accounted for (Wittrock et al., 2006). In this work, an optimized procedure to consider this liquid water absorption in the DOAS fit has been set up (see details in Sect. 2.1.2). In the glyoxal fitting window, a polynomial of degree 2 efficiently removes the broad-band spectral structures and one supplementary parameter allows for correcting possible constant intensity offset in the measured spectra. Also, the wavelength grid of the earthshine spectrum is shifted in order to properly align the Fraunhofer lines present in the radiance to those in the irradiance spectrum.

The typical order of magnitude of the glyoxal SCDs is 0.5$1.5 \times 10^{15} \mathrm{molec} / \mathrm{cm}^{2}$ making its optical density very small compared to the other absorbers in this spectral region (e.g. 
Table 1. Reference cross-section data sets included in the glyoxal DOAS retrievals.

\begin{tabular}{ll}
\hline Specie & Reference \\
\hline Glyoxal (CHOCHO) & Volkamer et al. (2005a) \\
Ozone $\left(\mathrm{O}_{3}\right)$ & Burrows et al. (1999) \\
Nitrogen Dioxide $\left(\mathrm{NO}_{2}\right)$ & Vandaele et al. (1998) \\
Water Vapour $\left(\mathrm{H}_{2} \mathrm{O}\right)$ & Rothman et al. (2005) \\
$\mathrm{O}_{2}-\mathrm{O}_{2}$ collision pair & Greenblatt et al. (1990); \\
& shifted by 0.2 nm. \\
Ring (as peudo-absorber) & Chance and Spurr (1997) \\
Liquid Water & Pope and Fry (1997) \\
\hline
\end{tabular}

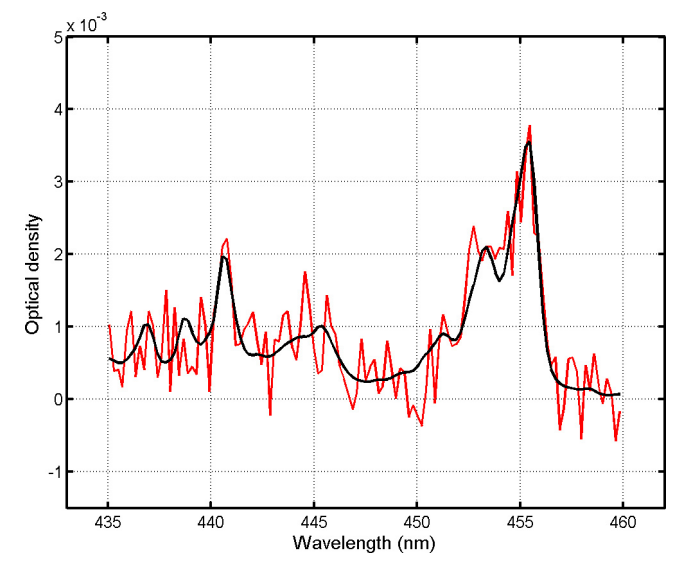

Fig. 1. DOAS fit of the glyoxal optical density for a GOME-2 measurement recorded on 16 March 2007 close to Hanoi (Vietnam). The black curve represents the reference glyoxal crosssection scaled by the fitted SCD $\left(6.57 \times 10^{15} \mathrm{molec} / \mathrm{cm}^{2}\right)$. The red curve represents the fit residuals superimposed to the glyoxal optical density.

the $\mathrm{NO}_{2}$ optical density is 10 times larger). In addition, glyoxal is mostly present in the boundary layer where the satellite sensitivity is small. Consequently, glyoxal detection using spaceborne sensors is to a large extent limited by the signal-to-noise ratio of the radiance and irradiance measurements. The detection limit (defined as three times the random error; see Sect. 3) for an individual slant column density measurement is estimated at about $2 \times 10^{15} \mathrm{molec} / \mathrm{cm}^{2}$. This can be further decreased by averaging measurements in time and/or space. Figure 1 shows an example of glyoxal DOAS fit for an individual GOME-2 scene recorded in March 2007 close to Hanoi (Vietnam). The associated SCD is very high $\left(6.57 \times 10^{15} \mathrm{molec} / \mathrm{cm}^{2}\right)$, as a result of high biomass burning emissions over southeastern Asia in springtime.

\subsubsection{Impact of liquid water absorption}

Figure 2 (upper panel) illustrates the monthly mean glyoxal slant columns measured in December 2008 when the liquid water absorption is not considered in the DOAS re-
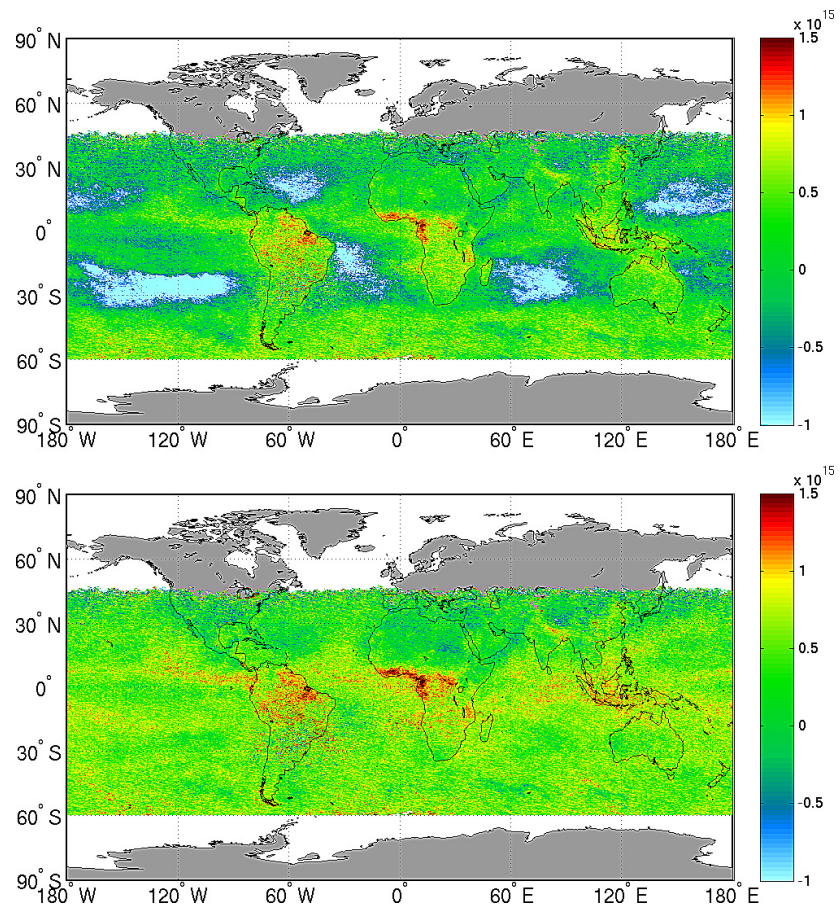

Fig. 2. Monthly mean of glyoxal SCDs $\left(\right.$ molec $\left./ \mathrm{cm}^{2}\right)$ measured by GOME-2 in December 2008. The upper and lower panels respectively show the columns retrieved without and with the liquid water absorption included in the DOAS fit. Pixels in polar regions and/or with solar zenith angles larger than $70^{\circ}$ have been excluded.

trievals. As already noted in Wittrock et al. (2006), the glyoxal columns above remote oceans are systematically negative and the quality of the fits in these regions is poorer as shown by the high value of the root mean square of glyoxal DOAS residuals (Fig. 3, blue line). This artifact has been attributed to interferences between the glyoxal and liquid water absorption spectra, which are significant in clear water regions where the light path below the surface is not negligible (Smith and Mobley, 2007; Jin and Charlock, 2001; Jin et al., 2004). Because of these spectral interferences, the simultaneous adjustment of glyoxal and liquid water slant column densities in the DOAS fit leads to unphysical results.

To take into account the liquid water absorption in the glyoxal retrievals, a solution in two steps has been designed. First, the liquid water optical density is measured using a wider DOAS fitting window $(405-490 \mathrm{~nm})$, which allows for using the broad features of the liquid water cross-section. Only the ozone and $\mathrm{O}_{2}-\mathrm{O}_{2}$ cross-sections are included in this retrieval in addition to the liquid water reference crosssection from Pope and Fry (1997). Figure 4 gives an example of the liquid water optical density fit. The change in slope observed around $450 \mathrm{~nm}$ is responsible for the interferences between glyoxal and liquid water when simultaneously adjusted. Figure 5 shows a map of the monthly mean liquid water optical densities retrieved in December 2008. High 


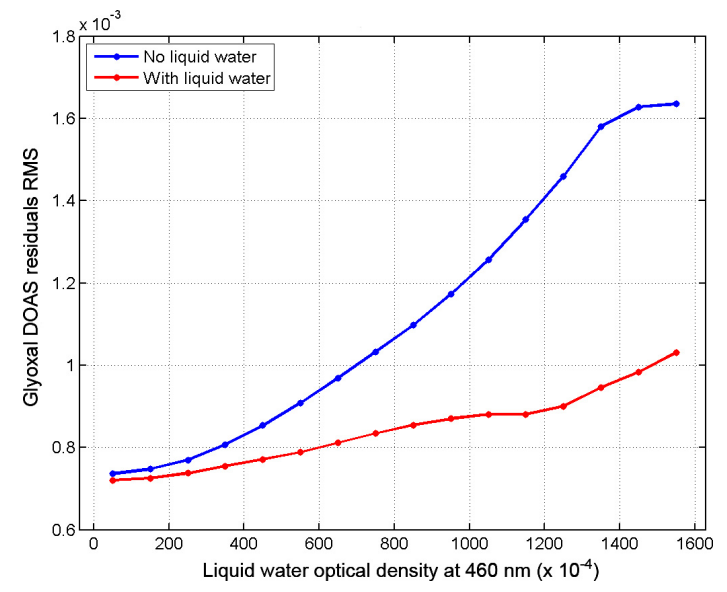

Fig. 3. Averaged root mean square of glyoxal DOAS residuals for all GOME-2 measurements of 5 December 2008 as a function of the liquid water optical density. Considering the liquid water absorption in the glyoxal retrievals significantly improves the fit quality.

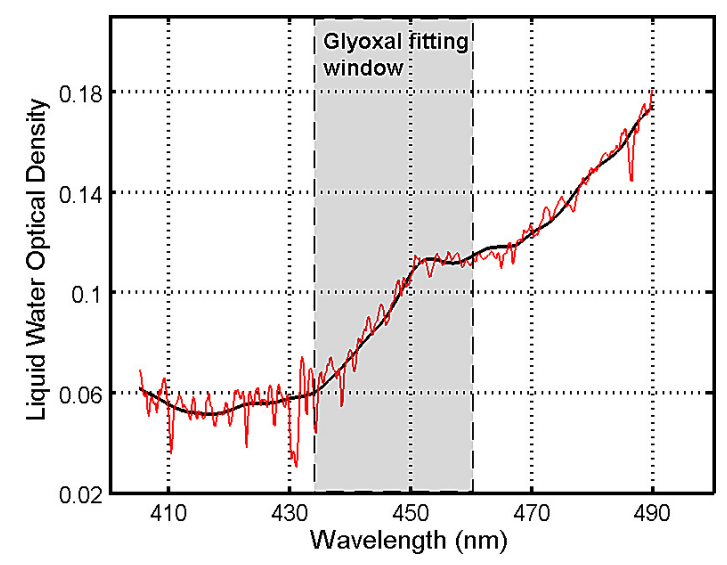

Fig. 4. DOAS fit of the liquid water optical density based on GOME-2 spectra recorded on 16 March 2007 in the Pacific Ocean. The calculated optical density is represented by the black curve and the fit residuals are plotted in red.

values perfectly correlate with the oceanic regions where the glyoxal retrievals fail when the liquid water absorption is not included in the fit (Fig. 2). These regions are characterized by a very low concentration of chlorophyll, which absorbs in the visible region. The light path below the sea surface is consequently more important there than in other oceanic regions.

The second step consists in retrieving the glyoxal SCD in the $435-460 \mathrm{~nm}$ interval fixing the liquid water optical density to the value determined in the large fitting window (Fig. 4). This two-step method allows for considering the liquid water absorption with a minimum impact of spectral interferences on the glyoxal fits. The lower panel of Fig. 2 clearly shows that glyoxal columns over oceans retrieved using this method are much more physical. Also, the DOAS

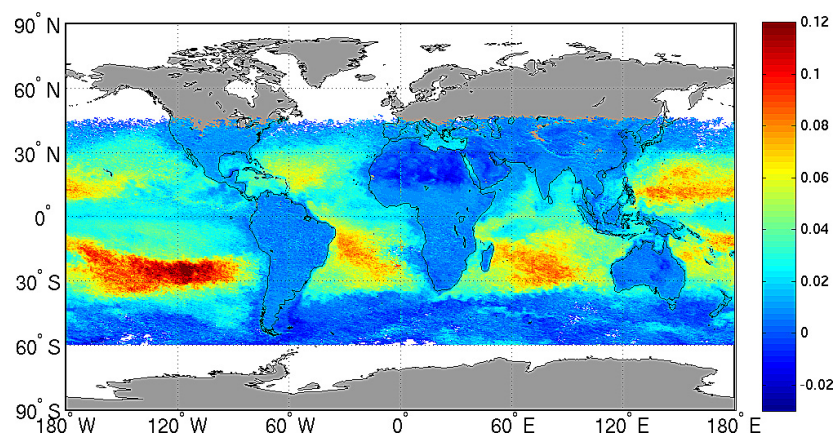

Fig. 5. Monthly mean liquid water optical density at $460 \mathrm{~nm}$ retrieved in December 2008.

fit quality in these regions is greatly improved (Fig. 3). Nevertheless, a slight increase of the residuals with increasing liquid water optical density remains despite our correction procedure. This indicates either uncertainties in the reference liquid water cross-sections or the existence of another physical effect specific to the oceanic regions affecting the photons along their light path (e.g. vibrational Raman scattering; Vasilkov et al., 2002). Note finally that the impact of this correction over lands is relatively limited due to the small liquid water optical densities measured in these regions.

\subsubsection{Reference irradiance spectrum}

The daily irradiance spectra measured by GOME-2 are used to calculate the atmospheric transmittance in the DOAS retrievals. However, their usage introduces yearly reproducible time-dependent offsets in the retrieved glyoxal slant columns. Test retrievals carried out using a fixed irradiance spectrum show much smoother temporal variations in the glyoxal SCDs (Fig. 6), pointing to a problem related to the irradiance spectra. Similar patterns have been observed in DOAS retrievals based on measurements from the GOME/ERS-2 instrument. In that case, they originated from spectral artefacts in the GOME irradiance spectra, caused by angular dependent small scale spectral features in the reflectivity of the diffusor plate used for the solar measurements (Richter and Wagner, 2001).

To sidestep this problem, a daily normalization procedure based on measurements in remote areas has been established, as commonly used for minor trace gas retrievals (e.g. Richter and Burrows, 2002; Martin et al., 2002; De Smedt et al., 2008). In this procedure, a general offset is applied to all retrieved glyoxal SCDs so that the mean vertical column of the clear sky pixels in the remote Pacific Ocean is equal to $1 \times 10^{14} \mathrm{molec} / \mathrm{cm}^{2}$. The Pacific reference sector is taken between $135^{\circ} \mathrm{W}$ and $180^{\circ} \mathrm{W}$, and comprises all latitudes except the tropical region $\left(25^{\circ} \mathrm{S}-25^{\circ} \mathrm{N}\right)$ where the glyoxal columns are higher (see Sect. 5). With this normalization, it is assumed that there is no seasonal variation in the mean level of glyoxal in the reference sector. The normalization value 

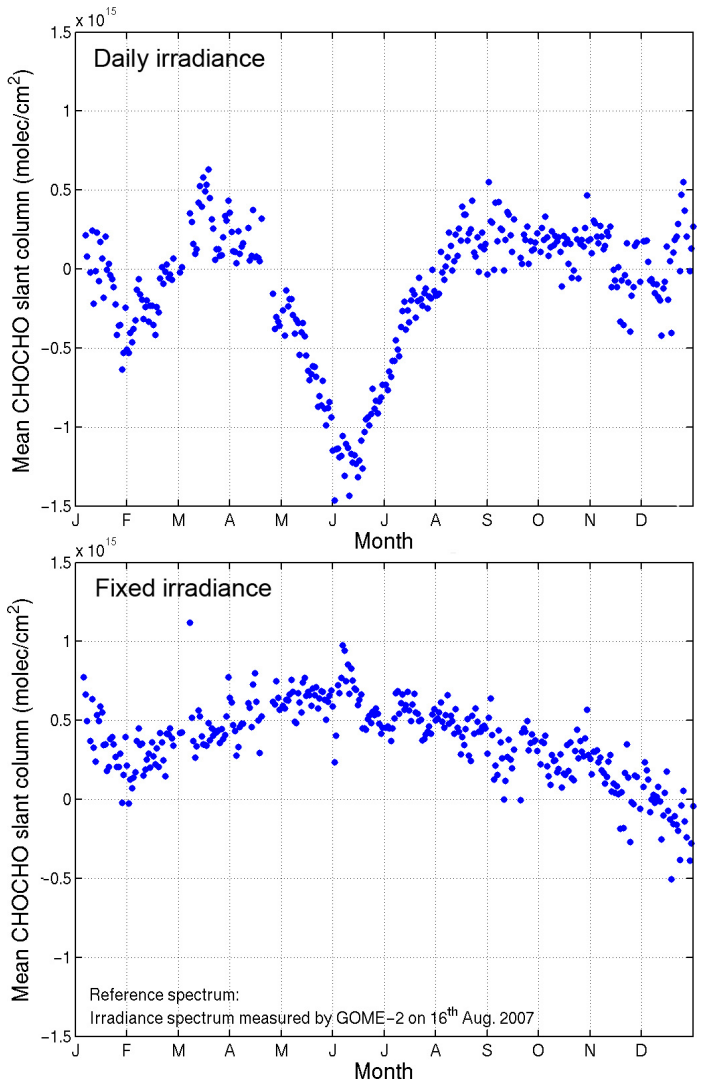

Fig. 6. Time variation of the glyoxal SCDs daily averaged in the sector $\left(15^{\circ} \mathrm{N}-45^{\circ} \mathrm{N} ; 30^{\circ} \mathrm{W}-60^{\circ} \mathrm{W}\right)$ in 2007 . The upper panel shows the results retrieved using the daily GOME-2 irradiance spectra; those obtained using a fixed irradiance spectrum (recorded by GOME-2 on 16 August 2007) are presented in the lower panel.

of $1 \times 10^{14} \mathrm{molec} / \mathrm{cm}^{2}$ is roughly consistent with the nonnormalized vertical column measurements averaged in the reference sector during periods with minimum impact of the irradiance artefacts.

\subsection{Conversion into vertical column densities}

The air mass factor (AMF), defined as the ratio of the SCD to the VCD (vertical column density), can be calculated by means of a radiative transfer model. Glyoxal being a weak absorber, the formulation of Palmer et al. (2001) for the AMF can be used:

$\mathrm{AMF}=\frac{\int_{0}^{\infty} \mathrm{WF}(z) \mathrm{S}(z) d z}{\int_{0}^{\infty} \mathrm{S}(z) d z}$,

where WF represents the scattering weights or weighting functions and $\mathrm{S}$ is the a priori glyoxal concentration at the altitude $z$. This formulation presents the advantage to decouple the instrumental sensitivity to scattered light from the trace gas concentration vertical distribution. Look-up tables of altitude-resolved weighting functions at $448 \mathrm{~nm}$ have been generated using the LIDORTv3.3 radiative transfer model (Spurr, 2008). These tables account for the observation geometry, the surface altitude and the surface albedo. For each pixel, the surface elevation is taken from the ETOPO2v2 Global Gridded 2-minute Database (http: //www.ngdc.noaa.gov/mgg/global/etopo2.html) and the surface albedo at $440 \mathrm{~nm}$ is provided by the climatology of Koelemeijer et al. (2003).

The a priori glyoxal concentration profiles are provided by the IMAGESv2 chemical transport model (CTM) (see Sect. 4). These profiles are calculated on a monthly basis at the horizontal resolution of $2^{\circ} \times 2.5^{\circ}$ and on 40 vertical levels from the surface up to the pressure level of $44 \mathrm{hPa}$. Using model profiles presents the advantage to have seasonal and geographical dependencies of the profile shape. Nevertheless, there may be important uncertainties in the CTM a priori profiles, especially over oceanic regions where the formation processes are not well represented, making thereby important a proper characterization of the errors (cf. Sect. 3).

Cloud contamination of pixels usually prevents probing the lower tropospheric part of the atmosphere with spaceborne instruments. Therefore, a cloud correction based on the independent pixel approximation (Martin et al., 2002) is applied to calculate the glyoxal vertical columns. The VCD computation is based on the formulation given in e.g. Van Roozendael et al. (2006):

$\mathrm{VCD}=\frac{\mathrm{SCD}+\Phi \mathrm{GC} \mathrm{A}_{\text {cloud }}}{(1-\Phi) \mathrm{A}_{\text {clear }}+\Phi \mathrm{A}_{\text {cloud }}}=\frac{\mathrm{SCD}+\Phi \mathrm{GC} \mathrm{A}_{\text {cloud }}}{\mathrm{A}_{\text {tot }}}$,

where $\Phi$ is the intensity-weighted cloud fraction, GC is the so-called ghost column accounting for the glyoxal column shielded by the cloud and calculated using the a priori profiles. $A_{\text {clear }}$ and $A_{\text {cloud }}$ are respectively the air mass factors for the clear and cloudy parts of the pixel calculated using Eq. (1) where the integration is performed down to the ground or to the cloud top height. In case of cloud contamination, calculating the cloudy $\mathrm{AMF}$ in this way requires the adding of an explicit ghost column correction to the slant column (see Eq. 2). The cloud parameters are provided by the FRESCO+ cloud algorithm (Wang et al., 2008), that retrieves the effective cloud fraction and cloud top height assuming a Lambertian cloud with an albedo of 0.8. Although no explicit correction for aerosols is applied, the cloud algorithm implicitly accounts for a possible contribution from reflecting aerosols by retrieving higher effective cloud fractions (Boersma et al., 2004). In addition, Leitão et al. (2010) found that neglecting aerosols leads to moderate errors in most cases. However, these errors might be more important in case of high absorbing aerosol content during large biomass burning events or in heavily polluted megacities and need to be further investigated. 


\section{Error budget}

A comprehensive error budget has been performed using the formalism presented in De Smedt et al. (2008). Assuming uncorrelated errors, the total error on individual glyoxal VCD measurements may be expressed as the sum of random and systematic errors on the SCD, AMF and ghost column correction (Boersma et al., 2004):

$$
\begin{aligned}
\sigma_{\text {tot }}^{2} & =\frac{\sigma_{\mathrm{S}, \text { rand }}^{2}+\sigma_{\mathrm{S}, \text { syst }}^{2}+\Phi^{2} \mathrm{~A}_{\text {cloud }}^{2} \sigma_{\mathrm{GC}}^{2}}{\mathrm{~A}_{\text {tot }}{ }^{2}} \\
& +\left(\frac{\mathrm{SCD}+\Phi \mathrm{A}_{\text {cloud }} \mathrm{GC}}{\mathrm{A}_{\mathrm{tot}}{ }^{2}}\right)^{2} \sigma_{A}^{2},
\end{aligned}
$$

where $\sigma_{\mathrm{S} \text {, rand }}$ and $\sigma_{\mathrm{S} \text {,syst }}$ are the random and systematic errors on the slant column, $\sigma_{\mathrm{GC}}$ is the error on the ghost column correction and $\sigma_{A}$ is the error on the total air mass factor $\mathrm{A}_{\text {tot }}$.

Considering individual measurements, the SCD random errors $\left(\sigma_{\mathrm{S} \text {,rand }}\right)$ are dominant and are found to range between $7 \times 10^{14}$ and $13 \times 10^{14} \mathrm{molec} / \mathrm{cm}^{2}$ depending on the observation geometry, the scene reflectivity, and also the age of the satellite and the status of its degradation. When measurements are averaged at cost of temporal and/or spatial resolution, this random error is strongly reduced (by the square root of the number of measurements).

The systematic errors on the slant column densities $\left(\sigma_{\mathrm{S}, \text { syst }}\right)$ mainly originate from uncertainties in the reference cross-section data sets and their cross-correlations. The uncertainties associated to the glyoxal cross-sections have been estimated to be less than 5\% (Volkamer et al., 2005a). In addition, the uncertainties in the other cross-section data sets included in the DOAS fit also contribute to the systematic errors via their cross-correlations with the glyoxal spectrum. Their respective contributions have been estimated with a set of DOAS analysis using alternative reference data sets for each of the species. Also, the total systematic errors associated to each measurement have been calculated using the formalism of Rodgers (2000) and are consistent with the results derived from the sensitivity tests (see also Theys et al. (2007); De Smedt et al. (2008)). In the calculation of $\sigma_{\mathrm{S} \text {, syst }}$, a term takes into account the contribution of the error propagated from the liquid water optical density retrieval. In general, $\sigma_{\mathrm{S} \text {, syst }}$ is estimated at $2-3 \times 10^{14} \mathrm{molec} / \mathrm{cm}^{2}$ in regions where the liquid water absorption is negligible while it can reach $4-5 \times 10^{14} \mathrm{molec} / \mathrm{cm}^{2}$ in clear water oceanic regions.

The accuracy of the ghost column correction depends on the quality of the a priori profiles. The differences between the a priori IMAGES vertical columns and monthly mean of co-located GOME-2 clear sky measurements are used to estimate $\sigma_{\mathrm{GC}}$, which strongly depends on the location, the measurement time and obviously on the cloud contamination. In particular, $\sigma_{\mathrm{GC}}$ is very large for pixels strongly contaminated by high-altitude clouds in regions where the a priori column greatly differs from temporally and spatially close clear
Table 2. Uncertainties associated to the profile shape parameters.

\begin{tabular}{lcc}
\hline Profile Parameter & Land Pixels & Ocean Pixels \\
\hline Peak Altitude & $0.5 \mathrm{~km}$ & $3 \mathrm{~km}$ \\
Profile Width & $2 \mathrm{~km}$ & $10 \mathrm{~km}$ \\
\hline
\end{tabular}

sky measurements. In general, $\sigma_{\mathrm{GC}}$ ranges between 0 and $3 \times 10^{14} \mathrm{molec} / \mathrm{cm}^{2}$. In oceanic regions, the very important profile shape uncertainties (see below) may also contribute to the ghost column error. However, this supplementary term is difficult to assess due to the lack of knowledge of glyoxal production processes in these regions.

To estimate the AMF error $\left(\sigma_{A}\right)$, the uncertainties associated to the AMF calculation input parameters as well as the AMF sensitivity to each of them have to be assessed. Assuming uncorrelated parameter uncertainties and neglecting the geolocation errors, $\sigma_{A}$ can be written as (Boersma et al., 2004; De Smedt et al., 2008):

$\sigma_{A}^{2}=\sum_{\mathrm{p}}\left(K_{\mathrm{p}} \sigma_{\mathrm{p}}\right)^{2}$

where $\sigma_{\mathrm{p}}$ is the uncertainty associated to the AMF calculation input parameter $p$ and $K_{\mathrm{p}}$ is the AMF derivative with respect to $p$. In this relation, uncertainties on the cloud parameters (cloud fraction and cloud top height), on the surface albedo and on the profile shape are considered. Koelemeijer et al. (2003) have estimated the surface albedo absolute uncertainty to 0.02 . The cloud fraction and cloud top height uncertainties are estimated to 0.05 and $1 \mathrm{~km}$, respectively (Koelemeijer et al., 2001). The uncertainties on the IMAGES profile shapes are difficult to assess due to the lack of independant glyoxal measurements. Consequently, high values have been arbitrarily attributed to the uncertainties associated to the peak altitude and width of the profile (Table 2), which probably lead to an overestimation of the AMF error. Over oceans, the uncertainties are still more important since the model largely underestimates the satellite glyoxal columns (see Sect. 5). The AMF derivatives with respect to input parameters $\left(K_{\mathrm{p}}\right)$ have been calculated for many scenarios representative of all possible observation geometries, glyoxal vertical distributions, cloud contaminations and surface reflectivities. These derivatives are stored in look-up tables making possible a fast computation of $\sigma_{A}$. Figure 7 illustrates the cloud fraction dependence of the AMF considering a cloud top height of $2 \mathrm{~km}$ and for two opposite glyoxal profiles: one peaking at the surface and the other being constant in the troposphere. This dependence is very strong at low cloud fractions, making the AMF error due to the cloud fraction uncertainty much higher in this regime. It is also clear that the impact of profile shape uncertainties on the AMFs is much more important for clear-sky pixels than for cloudcontaminated pixels. 


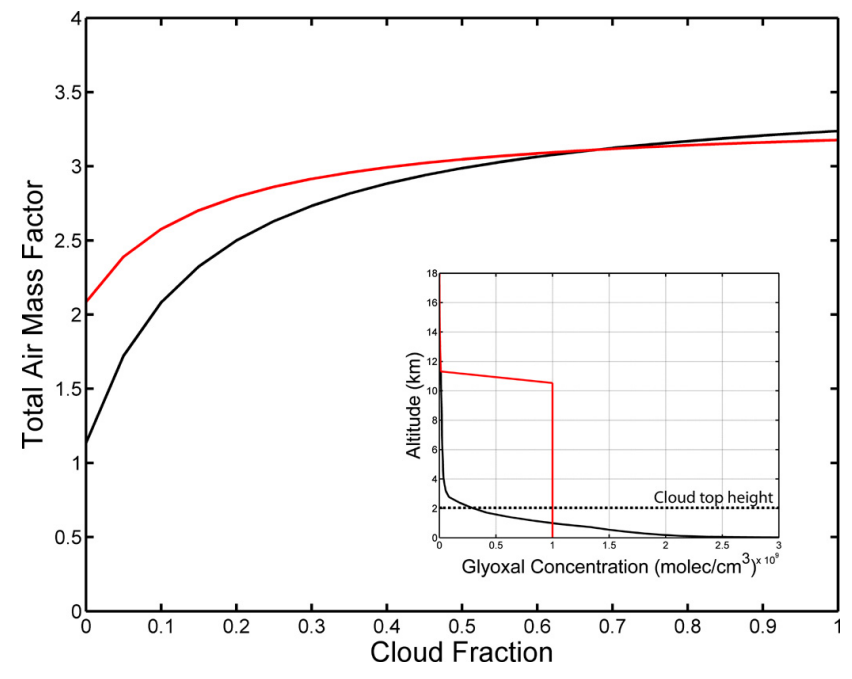

Fig. 7. Cloud fraction dependence of the total air mass factor calculated with a glyoxal profile strongly peaking at the surface (black curve) or with an unrealistic constant glyoxal profile in the troposphere (red curve). The corresponding profiles are plotted in the inner figure and the peaked profile is provided by the model IMAGESv2 for the region of Beijing on 1 July 2007. In these AMF calculations, the $\mathrm{SZA}$ is $50^{\circ}$, the surface albedo is 0.03 and the top height of the Lambertian cloud is $2 \mathrm{~km}$ (dashed line in the inner figure).

In general, the total absolute errors range between $2 \times 10^{14}$ and $3 \times 10^{14} \mathrm{molec} / \mathrm{cm}^{2}$ corresponding to relative errors around $40 \%$ in the high glyoxal concentration regions. Figure 8 shows mean total errors associated to the glyoxal VCD measurements in March 2007 and in two different regions, as well as the respective contribution of the different error components. In this figure, the random errors have been omitted, since they become negligible when a large number of measurements are averaged. The dominant errors strongly depend on the observation conditions. In particular, the contributions from the AMF errors and from the DOAS systematic errors decrease with increasing cloud fraction while the ghost column correction errors expectedly show the opposite behaviour. Despite reasonable total errors, it is recommended not to use the pixels strongly contaminated by clouds as their associated measured column is mostly influenced by the a priori information via the ghost column correction, especially for scenes containing high-altitude clouds. In practice, we filter out all pixels with a cloud fraction larger than $40 \%$, this threshold resulting from a trade-off between number of measurements and limited cloud contamination.

\section{Glyoxal simulated with the IMAGESv2 CTM}

A comprehensive description of IMAGESv2 global chemical transport model is given in Stavrakou et al. (2009a,b). Briefly, the model calculates the daily mean concentrations

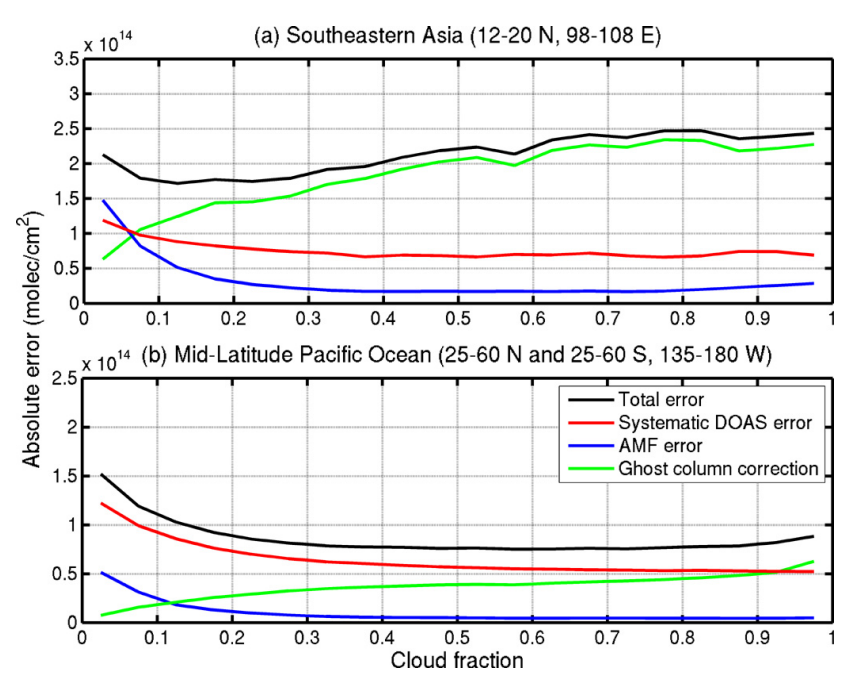

Fig. 8. Mean total errors associated to the glyoxal VCD retrieved from GOME-2 measurements in March 2007 (black) plotted as a function of the cloud fraction for (a) a continental and (b) an oceanic region. The contribution of the different types of errors is also illustrated: the contribution of the systematic errors in the DOAS fit (red); the contribution of the AMF error (blue) and the error associated to the ghost column correction (green). The random errors are negligible due to the large number of measurements.

of 117 compounds at a horizontal resolution of $2 \times 2.5$ degrees and on 40 vertical levels from the surface up to a pressure level of $44 \mathrm{hPa}$. The model transport is driven by ERAInterim meteorological fields. The model time step is equal to one day, whereas diurnal cycle simulations with a time step of $20 \mathrm{~min}$ are used to derive correction factors for the photolysis and kinetic rates, and the diurnal profiles required to estimate the glyoxal concentrations at the GOME-2 overpass time (09:30 LT).

Among the 22 NMVOCs included explicitly in the model, eight compounds, namely, isoprene, $\alpha$-pinene, glycolaldehyde, acetylene, ethene, and the aromatics (benzene, toluene, xylenes) are precursors of glyoxal. For isoprene, the MIM2+ chemical mechanism (Lelieveld et al., 2008; Butler et al., 2008) is used, whereas for the other species the oxidation scheme is designed so as to reproduce the glyoxal yields derived from box model simulations using the quasiexplicit Master Chemical Mechanism (http://mcm.leeds.ac. uk/MCM/home.htt, Saunders et al., 2003).

Compared to the model version used in Stavrakou et al. (2009b) several improvements have been introduced, especially concerning the input emission inventories. In particular, the annual anthropogenic NMVOC emissions are obtained from the RETRO database for 2000 (available at: retro.enes.org/data_emissions.shtml), except over Asia, where we use the REAS inventory for anthropogenic $\mathrm{CO}$, $\mathrm{NO}_{\mathrm{x}}$ and NMVOC emissions (Ohara et al., 2007). In addition, assuming that the categories "other alkanals" and "ketones" of the RETRO inventory consist of monofunctional 
compounds, the emissions of the bifunctional carbonyls glyoxal, methylglyoxal, glycolaldehyde, and 2,3-butanedione due to biofuel use are obtained based on burnt biomass estimate of the EDGARv3.3 inventory (Olivier et al., 2001; Olivier, 2002) and emission factors from Andreae and Merlet (2001) and updates from Andreae (2006) (pers. comm). The resulting global anthropogenic NMVOC source amounts to $155 \mathrm{Tg} / \mathrm{yr}$, including $1.6 \mathrm{Tg} / \mathrm{yr}$ of glyoxal due to biofuel. The seasonality of NMVOC emissions is neglected, except for a small component associated to biofuel use which is based on the heating degrees days approach. Although the fractional contribution of the residential/commercial sector is known from the EDGARv3.3 inventory, the contribution of heating is unavailable. Here we assume that the fraction $f_{\text {heating }}$ of residential emissions which is due to heating can be calculated from the annual number of degree days ( $H_{\mathrm{y}}$ in $k$ days): $f_{\text {heating }}=H_{\mathrm{y}} /\left(H_{\mathrm{y}}+500\right)$.

An updated version of the MEGAN-ECMWF inventory (Müller et al., 2008) for isoprene emissions is used, driven by ERA-Interim meteorological fields, instead of operational ECMWF analyses as in Müller et al. (2008). It spans the years between 1996 and 2009 and is fully accessible at the MEGAN-ECMWF website (http://tropo.aeronomie.be/ models/mohycan.htm). The global annual isoprene emissions are estimated at 420,403 and $424 \mathrm{Tg} / \mathrm{yr}$ for the years 2007, 2008 and 2009, respectively. Monthly vegetation fire emissions are obtained from the newly released version 3.1 of the Global Fire Emission Database (GFED, http: $/ /$ www.falw.vu/ $\sim$ gwerf/GFED/index.html). This dataset accounts for the distinction between emissions from savanna, woodland, and forest fires, agricultural waste burning, peatlands, deforestation and degradation fires (van der Werf et al., 2010). The annual global NMVOC fire emissions are estimated at $94.3 \mathrm{Tg} / \mathrm{yr}$ in $2007,76.5 \mathrm{Tg} / \mathrm{yr}$ in 2008 , and $68.8 \mathrm{Tg} / \mathrm{yr}$ in 2009.

Three-year long simulations are performed with a spin up time of 4 months starting on 1 September 2006. Besides the standard S0 simulation, we conduct four additional sensitivity studies to investigate the effect on the predicted glyoxal columns of doubling the global isoprene emissions (S1), neglecting the direct biofuel emission of glyoxal (S2), and halving (S3) or doubling (S4) the direct and indirect glyoxal production from biomass burning (Table 3 ).

\section{Results and discussion}

\subsection{Observed GOME-2 glyoxal vertical columns}

Averaged glyoxal vertical column densities retrieved from GOME-2 measurements between 2007 and 2009 are illustrated in Fig. 9, and seasonally averaged column maps are shown in Fig. 10. The highest annual columns (up to $8 \times 10^{14} \mathrm{molec} / \mathrm{cm}^{2}$ ) are observed over continental tropical regions, where biogenic and biomass burning NMVOC emis-
Table 3. Performed global model simulations.

\begin{tabular}{cl}
\hline Simulation & Description \\
\hline S0 & standard \\
S1 & double isoprene emissions \\
S2 & neglect the direct biofuel emission of glyoxal \\
S3 & half direct and indirect glyoxal production \\
& from fires \\
S4 & double direct and indirect glyoxal \\
& production from fires \\
\hline
\end{tabular}

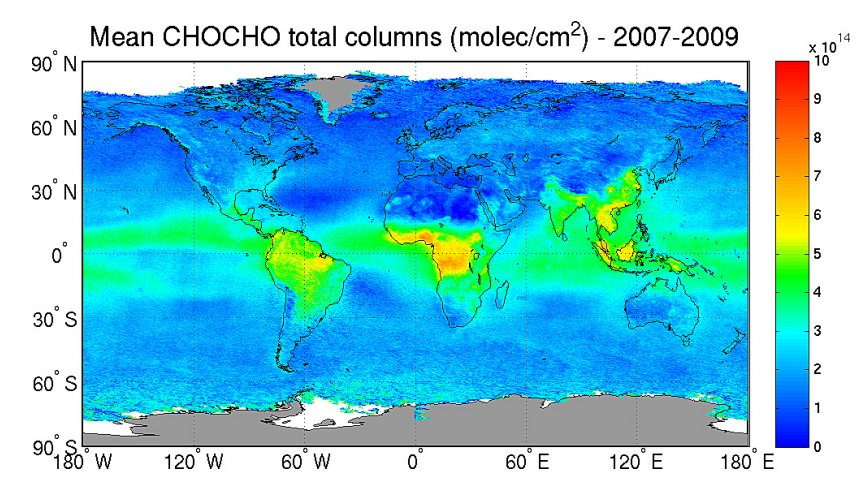

Fig. 9. Mean glyoxal vertical column densities retrieved from GOME-2 measurements between 2007 and 2009. Only pixels with cloud fraction lower than 0.4 are considered.

sions are most important. Outside the Tropics, the mean glyoxal VCDs are lower and depend strongly on the season, reflecting the seasonal patterns in the emissions of glyoxal precursors and especially isoprene. In general, the observed glyoxal fields qualitatively agree with those recently measured by Vrekoussis et al. (2010), except over remote oceans where their columns are low-biased due to the glyoxal-liquid water spectral interferences.

Overall, the glyoxal vertical columns increase during the local summer months. In the southeastern US and in Europe, the mean $\mathrm{CHOCHO}$ columns reach respectively $6 \times 10^{14} \mathrm{molec} / \mathrm{cm}^{2}$ and $3.5 \times 10^{14} \mathrm{molec} / \mathrm{cm}^{2}$ in summertime, while they are close to $1 \times 10^{14} \mathrm{molec} / \mathrm{cm}^{2}$ in winter. A similar behaviour is observed over northern Australia, with maximal values $\left(\sim 5 \times 10^{14} \mathrm{molec} / \mathrm{cm}^{2}\right)$ during the local summertime and minima in wintertime. These variations are mostly due to the enhancement of biogenic emissions during the warm season.

In southeastern Asia, the situation is more complex since all different glyoxal emission sources contribute to the observed glyoxal columns. In general, marked seasonalities in biogenic and pyrogenic emissions are observed, with their respective peaking time being strongly dependent on the region of interest. For example, important biomass burning events take place in India every year in March-April, while such events occur generally around December in southern China 
(a) Dec-Jan-Feb

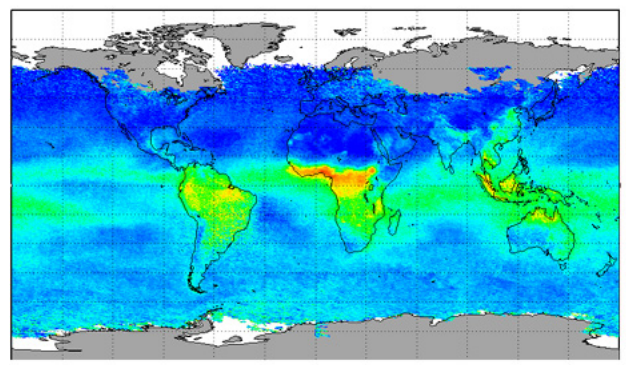

(c) Jun-Jul-Aug

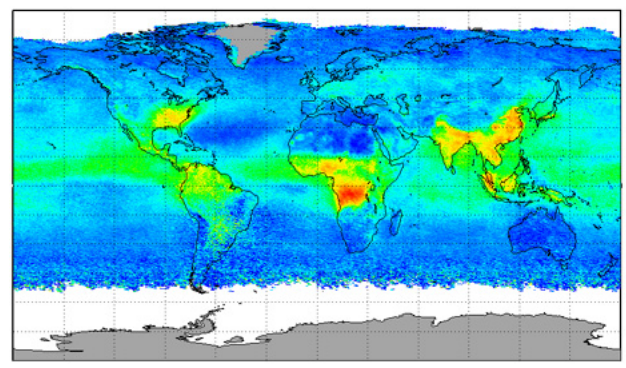

(b) Mar-Apr-May

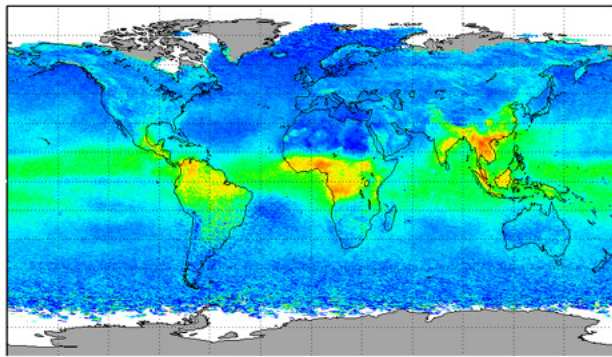

(d) Sep-Oct-Nov

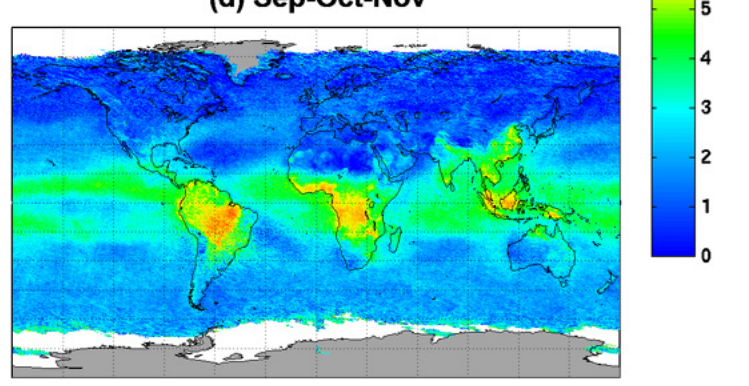

Fig. 10. Global maps of seasonally averaged vertical columns of glyoxal retrieved from GOME-2 measurements between 2007 and 2009.

(Vrekoussis et al., 2009). Furthermore, in highly populated regions of Asia, anthropogenic emissions of glyoxal and its precursors are significant. Figure 11 illustrates the spatial correlation between the population density from the GPW v3 (Gridded Population of the World) data set (Balk and Yetman, 2005) and the GOME-2 glyoxal vertical columns in winter, when the biogenic and pyrogenic emissions are at their lowest. Enhanced glyoxal column densities are clearly visible in the regions with the highest population density. In particular, high glyoxal columns are found in the regions of Beijing and Chongqing and in the Indo-Gangetic Plains. Also, very bright hot spots are observed over Hong-Kong, Shanghai and Bangkok. This indicates that the spatial resolution and the coverage of GOME-2 allows for resolving the anthropogenic signal in the measured glyoxal fields. In the next section, we will further investigate the origin of the observed glyoxal columns over China and southeastern Asia through sensitivity studies with the IMAGESv2 model.

In oceanic regions, the impact of the interferences between the liquid water and glyoxal absorption spectra is significantly reduced by our retrieval procedure. Indeed, as shown on Figs. 9 and 10, the glyoxal columns measured above clear water regions are positive (ca. $1 \times 10^{14} \mathrm{molec} / \mathrm{cm}^{2}$ ). Enhanced glyoxal VCDs are observed over the tropical oceans. Recently, ship measurements conducted in the Tropical Pacific Ocean using a MAX-DOAS instrument have clearly indicated elevated glyoxal concentrations in the marine boundary layer (Volkamer et al., 2010; Sinreich et al., 2010). Assuming a uniform glyoxal concentration in the marine boundary layer $(\mathrm{z}<700 \mathrm{~m}$, based on ECMWF analyses), the vertical column densities corresponding to these ship measurements reach $3 \times 10^{14} \mathrm{molec} / \mathrm{cm}^{2}$, consistent with our glyoxal observations from GOME-2 and those from SCIAMACHY (Vrekoussis et al., 2009). The causes for these high glyoxal abundances are still unknown. Typical known glyoxal precursors emitted over land are too short-lived to significantly contribute to such high glyoxal concentrations in remote oceans (Sinreich et al., 2010). However, the transport of (still unidentified) continental glyoxal precursors to oceanic regions cannot be totally excluded. Alternatively, as proposed by Vrekoussis et al. (2009), organic aerosols released from the sea might be oxidized in the boundary layer into gas-phase organic compounds. Further investigation is needed to elucidate the causes for the high glyoxal concentrations observed in tropical oceanic regions.

\subsection{Comparisons with the IMAGESv2 glyoxal columns}

The monthly averaged time series of the observed glyoxal columns and those simulated with the IMAGEv2 model over large areas in the mid-latitudes and in the Tropics between 2007 and 2009 are compared in Figs. 12 and 13. In both figures the standard S0 simulation is illustrated in black, and sensitivity calculations in color line.

Over mid-latitude regions the model reproduces generally quite well the seasonal pattern of the observed columns, their summertime enhancement and their winter minimum. In terms of absolute values, the simulated S0 columns are by about a factor of 2 lower in Europe with a less marked seasonal cycle than in the observation, whereas a much better agreement is achieved when isoprene emissions are doubled (S1). As in other regions (see below) the underestimation of 
(a) Mean Glyoxal VCDs in Winter $\left(\mathrm{molec} / \mathrm{cm}^{2}\right)$

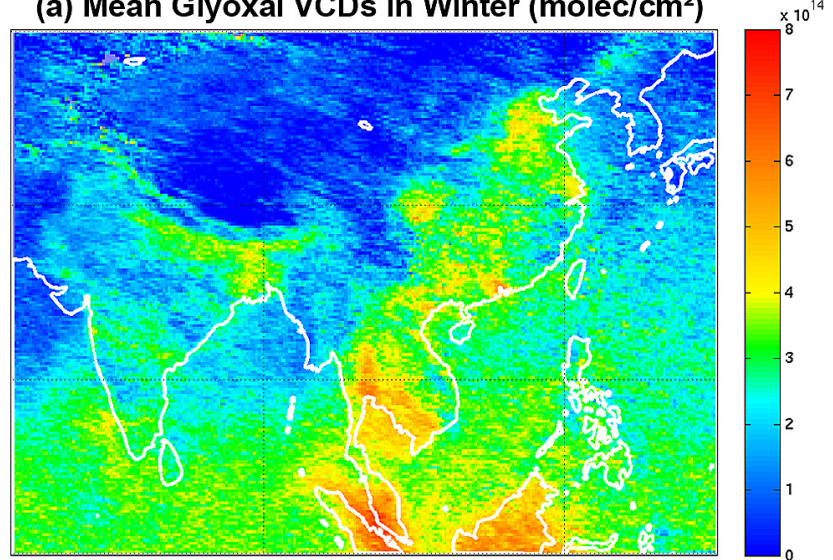

(b) Population density (persons $/ \mathrm{km}^{2}$ )

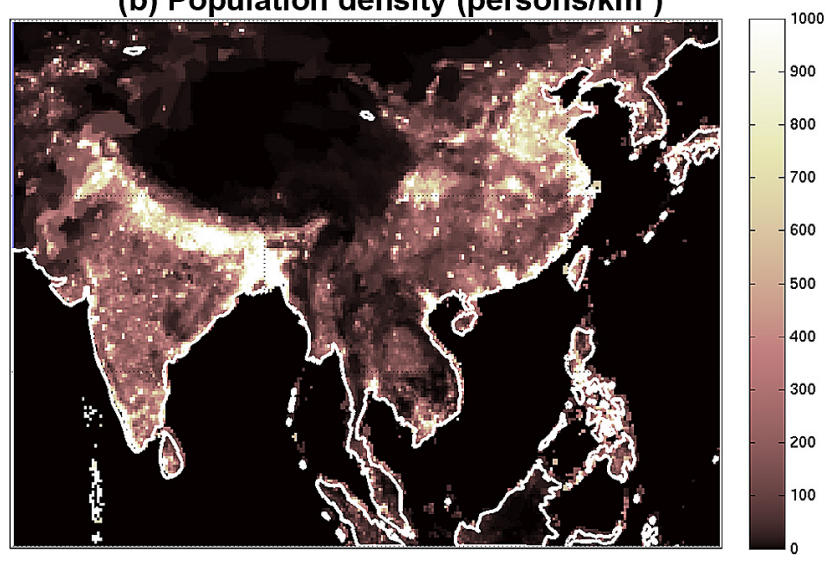

Fig. 11. Illustration of the mean glyoxal VCDs in winter (December-January-February) (upper panel) and the population density (lower panel) in southeastern Asian regions. The population density data are taken from the GPW v3 data set (Balk and Yetman, 2005).

glyoxal columns during the growing season suggests a possible underestimation in the glyoxal production from isoprene, or the existence of other biogenic glyoxal precursors with light and/or temperature dependent emissions.

The comparisons over the US show a very satisfactory agreement, in both the seasonal cycle and the magnitudes of the glyoxal columns (S0, Fig. 12, middle). Interestingly, the severe heat wave that occurred across the US throughout a large part of August 2007 is impressed on the peak values during this month in both the observed and the simulated glyoxal columns. Doubling the isoprene emissions used in the model leads to significant overestimations over the US (Fig. 12). It is worthy to note that recent findings, based on aircraft measurements (Warneke et al., 2010) and satellite columns of formaldehyde (Stavrakou et al., 2009a), rather suggest that the isoprene emissions over the US might be significantly overestimated in the MEGAN inventory. We cannot therefore exclude that the very good agreement between the observed and modelled (S0) columns might result from a compensation of errors, e.g. an overestimation of isoprene emissions and either an underestimation of the glyoxal yield from isoprene or the existence of other biogenic glyoxal precursors.

Over China, the model underprediction is quite important in summertime, even after doubling the isoprene source, although in this case the summertime seasonal variation is better captured. Again, this discrepancy puts forth the existence of an important unidentified source of glyoxal, most probably related to secondary production from glyoxal precursors emitted by plants (see also Stavrakou et al., 2009b). Furthermore, in constrast with the observed behaviour, the wintertime modelled columns of the standard run over China exhibit higher values than in summertime (Fig. 12 lower panels). A sensitivity test (S2) carried out by setting to zero the direct biofuel source of glyoxal leads to an important decrease of the modelled columns in wintertime, and improves significantly the correlation between the modelled and observed columns ( 0.25 in S0 vs. 0.85 in S2). This finding points to an overestimation in the biofuel use estimate over China in the EDGARv3.3 inventory, or more probably, in the utilized value $(1.12 \mathrm{~g} / \mathrm{kg}$ dry matter; M. O. Andreae, personal communication, 2006) for the biofuel emission factor for glyoxal.

For the tropical regions of Fig. 13, strong systematic underestimations are found especially during the wet season, except over Northern Australia, where the model lies reasonably close to the observation. Sensitivity simulations with halved (S3) or doubled (S4) biomass burning emissions of glyoxal and its precursors do not lead to a better agreement with the observed columns, as depicted in Fig. 13. The secondary peak observed every year in March-April over Indonesia and Amazonia, obviously not related to fire emissions, is intriguing. A doubling of the isoprene emissions (S1) provides only moderate column increases (not shown).

Note finally that strong uncertainties are present in the emission inventories, but also in the glyoxal formation yields from identified sources like isoprene. For example, the substantial revisions in the isoprene degradation mechanism recently proposed by Peeters et al. (2009); Peeters and Müller (2010) could strongly affect the glyoxal yield from isoprene, especially under low $\mathrm{NO}_{\mathrm{x}}$ conditions. Besides these uncertainties, the lack of knowledge about other potential sources of glyoxal constitutes a major difficulty, but also an incentive for further research.

\section{Conclusions}

Vertical column densities of glyoxal have been measured from the first three years of GOME-2/METOP-A observations (2007-2009). The retrieval algorithm, based on the DOAS technique, has been comprehensively described. In particular, the glyoxal slant column retrievals have been improved by accounting for the liquid water absorption, which 

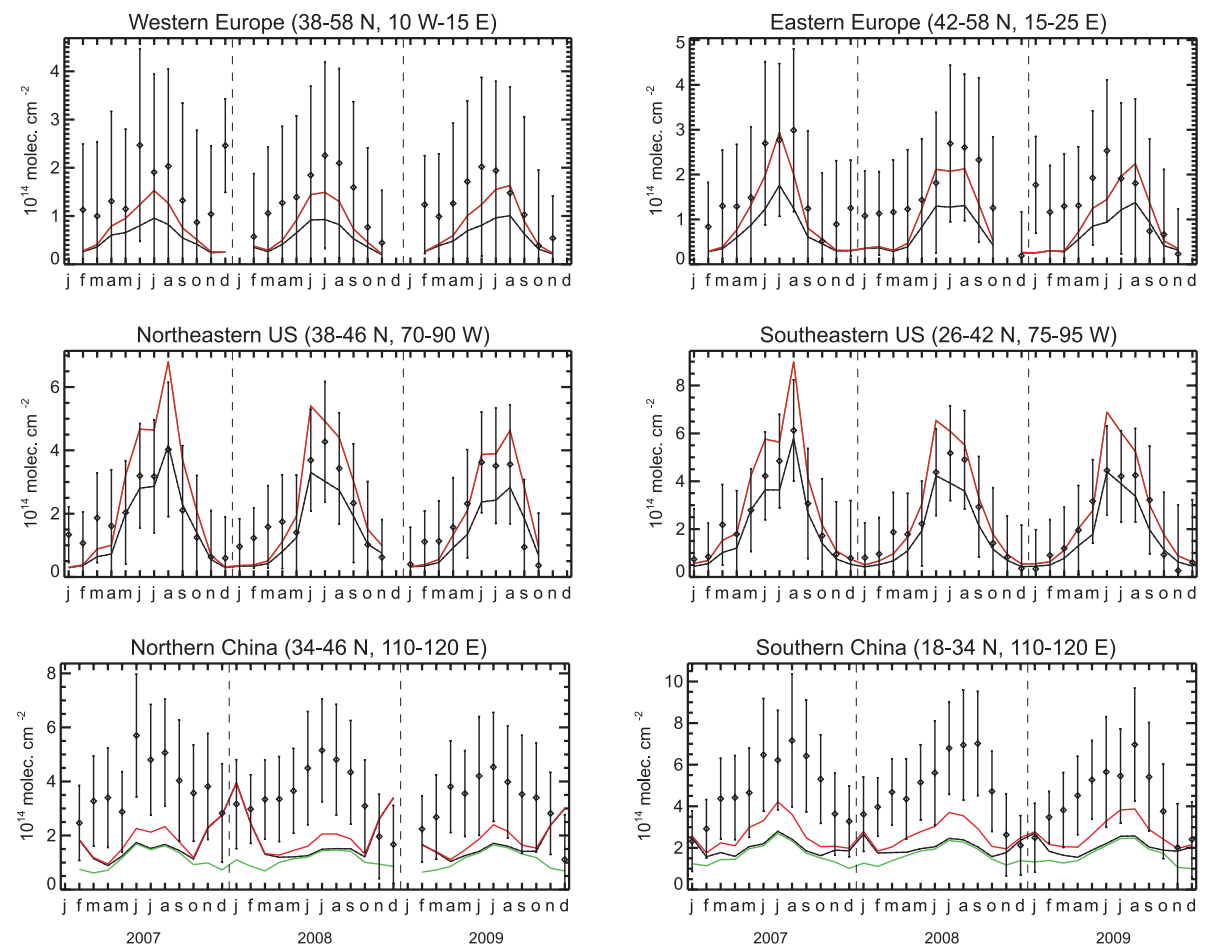

Fig. 12. Modelled and observed glyoxal column time series over selected large mid-latitude regions. The standard model simulation S0 is shown in black. The simulations S1 (with doubled isoprene emissions) and S2 (without the biofuel glyoxal source) are shown in red and green, respectively. Error bars represent the total errors on the observed columns as calculated in Sect. 3 .
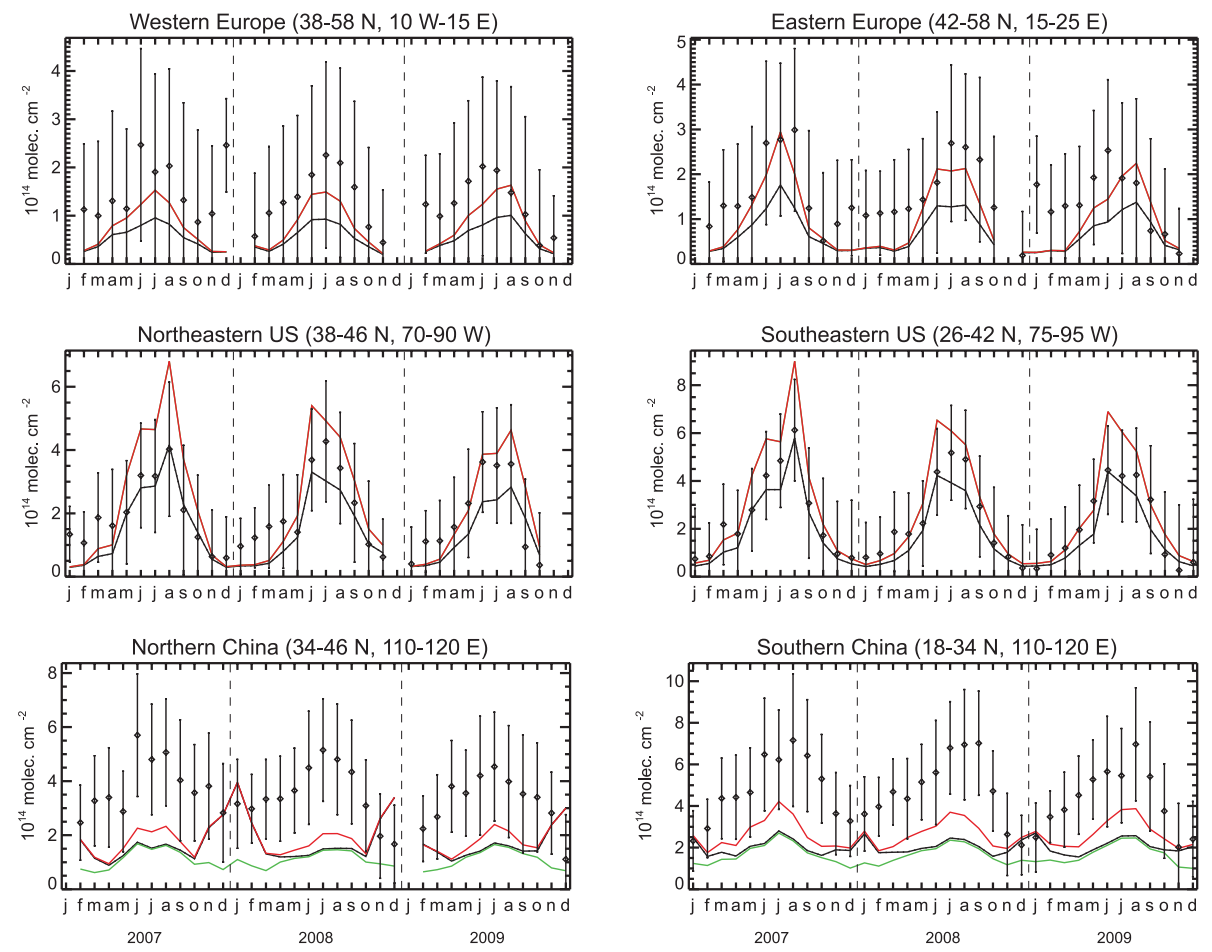

Fig. 13. Modelled and observed glyoxal column time series for selected tropical regions. The lines represent the standard simulation (in black) and the simulations with halved (S3 - in green) or doubled (S4 - in red) biomass burning emissions of glyoxal and its precursors. 
can be significant over remote oceans. Since the simultaneous adjustment of glyoxal and liquid water slant columns leads to unphysical results due to correlations between their respective absorption cross-sections, a specific two-step procedure has been designed: the liquid water slant column is firstly measured in a large fitting window $(405-490 \mathrm{~nm})$ and then used to determine the liquid water optical density in the fitting interval used for retrieving glyoxal $(435-460 \mathrm{~nm})$. This procedure improves the fit quality in clear water oceans and physical glyoxal columns are thus measured for the first time in these regions.

An error budget has been established considering the main error sources. Because of the very small optical density of glyoxal, the largest contribution to the total error is the random error in the slant column retrieval (up to $7 \times 10^{14} \mathrm{molec} / \mathrm{cm}^{2}$ ). However, this term can be strongly reduced by applying spatial and/or time averages of measurements. The other error sources add up, leading to total errors generally ranging between $2 \times 10^{14} \mathrm{molec} / \mathrm{cm}^{2}$ and $3 \times 10^{14} \mathrm{molec} / \mathrm{cm}^{2}(\sim 40 \%)$. Besides the random error, the systematic error in the DOAS fit and the AMF error are dominant for clear-sky scenes, while the error associated to the cloud-shielded glyoxal correction becomes larger at higher cloud fractions. Consequently, all pixels with large cloud fraction have to be used with care. The impact of absorbing aerosols has to be further investigated, especially because of their possible large concentrations during important fire events and in heavily polluted megacities.

The highest yearly mean vertical column densities are observed in tropical continental regions where biogenic and pyrogenic emissions are important. At mid-latitudes, the glyoxal columns strongly depend on the season, as a consequence of seasonal variations of biogenic emissions. In general, the glyoxal columns observed in these regions during wintertime are small. However, the columns measured over high population density regions remain significant all year round due to anthropogenic NMVOC emissions. Although the seasonality at mid-latitudes is generally well reproduced by the IMAGESv2 model, the simulated columns are generally biased low, especially during warm months. This underestimation suggests a missing source related to biogenic emissions. In China, the simulated columns overestimate the observations in winter, indicating a large overestimation of the direct glyoxal emission due to biofuel burning used in the CTM. In tropical regions, the simulated columns are generally much lower than the measurements, which points again to a large missing source associated to biogenic emissions. Finally, the current models are not able to reproduce the satellite glyoxal column observations over tropical oceans, which are in good consistency with recent ship glyoxal measurements.

More work is clearly needed to improve the representation of glyoxal sources and sinks in chemical transport models. Besides the large uncertainties associated to the emission inventories and to the glyoxal formation yields, the existence of unknown glyoxal precursors over land and ocean are required in order to reconcile the models with the observations. The large data set of glyoxal measurements presented here provides an important global reference and can be provided on request by the authors.

Accurate glyoxal ground-based measurements are also needed to validate the satellite data sets and to provide additional information unavailable to spaceborne instruments, like the vertical distribution or the diurnal dependence of the glyoxal concentrations. Furthermore, independent observations of glyoxal vertical distribution in different regions of the world (among which equatorial oceans) and in different seasons would help to better characterize the quality of the a priori profiles provided by current global models and to possibly improve these profiles which would lead to a reduction of the uncertainties associated to satellite measurements.

Acknowledgements. This research is partly funded by the Belgian Science Policy Office through the projects IBOOT (contract SD/AT/03, Science and Sustainable Development programme) and SECPEA (PRODEX). It has also been supported by ESA and the European Union via the PROMOTE and AMFIC projects. The authors acknowledge EUMETSAT for providing the GOME-2 level-1 data product.

Edited by: R. Volkamer

\section{References}

Andreae, M. O. and Merlet, P.: Emission of trace gases and aerosols from biomass burning, Global Biogeochem. Cy., 15, 955-966, 2001.

Balk, D. and Yetman, G.: Center for International Earth Science Information Network (CIESIN), Columbia University; United Nations Food and Agriculture Programme (FAO); and Centro Internacional de Agricultura Tropical (CIAT): Gridded Population of the World: Future Estimates (GPWFE). Palisades, NY: Socioeconomic Data and Applications Center (SEDAC), Columbia University, available at: http://sedac.ciesin.columbia.edu/gpw/, 2005.

Boersma, K. F., Eskes, H. J., and Brinksma, E. J.: Error analysis for tropospheric $\mathrm{NO}_{2}$ retrieval from space, J. Geophys. Res., 109, D04311, doi:10.1029/2003JD003962, 2004.

Burrows, J., Richter, A., Dehn, A., Deters, B., Himmelmann, S., Voigt, S., and Orphal, J.: Atmospheric remote sensing reference data from GOME: Part 2. Temperature-dependent absorption cross-sections of $\mathrm{O}_{3}$ in the 231-794 nm range, J. Quant. Spectrosc. Radiat. Transfer, 61, 509-517, 1999.

Butler, T. M., Taraborrelli, D., Brühl, C., Fischer, H., Harder, H., Martinez, M., Williams, J., Lawrence, M. G., and Lelieveld, J.: Improved simulation of isoprene oxidation chemistry with the ECHAM5/MESSy chemistry-climate model: lessons from the GABRIEL airborne field campaign, Atmos. Chem. Phys., 8, 4529-4546, doi:10.5194/acp-8-4529-2008, 2008.

Chance, K. and Spurr, R.: Ring effect studies: Rayleigh scattering including molecular parameters for rotational Raman scattering, and the Fraunhofer spectrum, Appl. Optics, 36, 5224-5230, 1997. 
De Smedt, I., Müller, J.-F., Stavrakou, T., van der A, R., Eskes, H., and Van Roozendael, M.: Twelve years of global observations of formaldehyde in the troposphere using GOME and SCIAMACHY sensors, Atmos. Chem. Phys., 8, 4947-4963, doi:10.5194/acp-8-4947-2008, 2008.

Ervens, B. and Volkamer, R.: Glyoxal processing by aerosol multiphase chemistry: towards a kinetic modeling framework of secondary organic aerosol formation in aqueous particles, Atmos. Chem. Phys., 10, 8219-8244, doi:10.5194/acp-10-8219-2010, 2010.

Fu, T., Jacob, D. J., Wittrock, F., Burrows, J. P., Vrekoussis, M., and Henze, D. K.: Global budgets of atmospheric glyoxal and methylglyoxal, and implications for formation of secondary organic aerosols, J. Geophys. Res., 113, D15303, doi:10.1029/2007JD009505, 2008.

Grainger, J. F. and Ring, J.: Anomalous Fraunhofer line profiles, Nature, 193, 762-762, doi:10.1038/193762a0, 1962.

Greenblatt, G. D., Orlando, J. J., Burkholder, J. B., and Ravishankara, A. R.: Absorption measurements of oxygen between 330 and 1140 nm, J. Geophys. Res., 95, 18577-18582, 1990.

Jin, Z. and Charlock, T.: Radiative Transfer Modeling of Ocean Surface Albedo for CERES SARB, in: Proceedings of 23rd CERES Science Team Meeting, Williamsburg, VA, USA, available online at: http://science.larc.nasa.gov/ceres/STM/2001-01/, 23-25 January, 2001.

Jin, Z., Charlock, T. P., Smith Jr., W. L., and Rutledge, K.: A parameterization of ocean surface albedo, Geophys. Res. Lett., 31, L22301, doi:10.1029/2004GL021180, 2004.

Koelemeijer, R. B. A., Stammes, P., Hovenier, J. W., and de Haan, J. F.: A fast method for retrieval of cloud parameters using oxygen A band measurements from the Global Ozone Monitoring Experiment, J. Geophys. Res., 106(D4), 3475-3490, 2001.

Koelemeijer, R. B. A., de Haan, J. F., Hovenier, J. W., and Stammes, P.: A database of spectral surface reflectivity in the range 335$772 \mathrm{~nm}$ derived from 5.5 years of GOME observations, J. Geophys. Res., 108(D2), 4070, doi:10.1029/2002JD002429, 2003.

Leitão, J., Richter, A., Vrekoussis, M., Kokhanovsky, A., Zhang, Q. J., Beekmann, M., and Burrows, J. P.: On the improvement of $\mathrm{NO}_{2}$ satellite retrievals - aerosol impact on the airmass factors, Atmos. Meas. Tech., 3, 475-493, doi:10.5194/amt-3-475-2010, 2010.

Lelieveld, J., Butler, T. M., Crowley, J. N., Dillon, T. J., Fischer, H., Ganzeveld, L., Harder, H., Lawrence, M. G., Martinez, M., Taraborrelli, D., and Williams, J.: Atmospheric oxidation capacity sustained by a tropical forest, Nature, 452, 737-740, 2008.

Martin, R. V., Chance, K., Jacob, D. J., Kurosu, T. P., Spurr, R. J. D., Bucsela, E., Gleason, J. F., Palmer, P. I., Bey, I., Fiore, A. M., Li, Q., Yantosca, R. M., and Koelemeijer, R. B. A.: An improved retrieval of tropospheric nitrogen dioxide from GOME, J. Geophys. Res., 107, 4437, doi:10.1029/2001JD001027, 2002.

Müller, J.-F., Stavrakou, T., Wallens, S., De Smedt, I., Van Roozendael, M., Potosnak, M. J., Rinne, J., Munger, B., Goldstein, A., and Guenther, A. B.: Global isoprene emissions estimated using MEGAN, ECMWF analyses and a detailed canopy environment model, Atmos. Chem. Phys., 8, 1329-1341, doi:10.5194/acp-81329-2008, 2008.

Munro, R., Eisinger, M., Anderson, C., Callies, J., Corpaccioli, E., Lang, R., Lefebvre, A., Livschitz, Y., and Albiñana, A. P.: GOME-2 on MetOp, in: Proceedings of The 2006 EUMETSAT
Meteorological Satellite Conference, Helsinki, Finland, 12-16 June 2006, 48, available at: http://www.eumetsat.int/, 2006.

Myriokefalitakis, S., Vrekoussis, M., Tsigaridis, K., Wittrock, F., Richter, A., Brühl, C., Volkamer, R., Burrows, J. P., and Kanakidou, M.: The influence of natural and anthropogenic secondary sources on the glyoxal global distribution, Atmos. Chem. Phys., 8, 4965-4981, doi:10.5194/acp-8-4965-2008, 2008.

Ohara, T., Akimoto, H., Kurokawa, J., Horii, N., Yamaji, K., Yan, X., and Hayasaka, T.: An Asian emission inventory of anthropogenic emission sources for the period 1980-2020, Atmos. Chem. Phys., 7, 4419-4444, doi:10.5194/acp-7-4419-2007, 2007.

Olivier, J .G. J., Berdowski, J. J. M., Peters, J. A. H. W., Bakker, J., Visschedijk, A. J. H., and Bloos, J.-P. J.: Applications of EDGAR. Including a description of EDGAR 3.0: reference database with trend data for 1970-1995, RIVM, Bilthoven, RIVM report no. 773301 001/NOP report no. 410200 051, 2001.

Olivier, J .G. J.: Part III: Greenhouse gas emissions. 1. Shares and trends in greenhouse gas emissions; 2. Sources and methods: greenhouse gas emissions for 1990 and 1995 in $\mathrm{CO}_{2}$ emissions from fuel combustion 1971-2000, International Energy Agency, Paris, ISBN 92-64-09794-5, 1-31, 2002.

Palmer, P., Jacob, D., Chance, K., Martin, R., Spurr, R., Kurosu, T., Bey, I., Yantosca, R., Fiore, A., and Li, Q.: Air mass factor formulation for spectroscopic measurements from satellites: Application to formaldehyde retrievals from the Global Ozone Monitoring Experiment, J. Geophys. Res., 106(D13), 14539-14550, 2001.

Palmer, P. I., Jacob, D. J., Fiore, A. M., Martin, R. V., Chance, K., and Kurosu, T. P.: Mapping isoprene emissions over North America using formaldehyde column observations from space, J. Geophys. Res., 108(D6), 4180, doi:10,1029/2002JD002153, 2003.

Peeters, J., Nguyen, T. L., and Vereecken, L.: HOx radical regeneration in the oxidation of isoprene, Phys. Chem. Chem. Phys., 11, 5935-5939, doi:10.1039/b908511d, 2009.

Peeters, J. and Müller, J.-F.: $\mathrm{HO}_{\mathrm{x}}$ radical regeneration in isoprene oxidation via peroxy radical isomerisations, II: Experimental evidence and global impact, Phys. Chem. Chem. Phys., 12, 1422714235, doi:10.1039/C0CP00811G, 2010.

Platt, U. and Stutz, J.: Differential Optical Absorption Spectroscopy: Principles and Applications. Physics of Earth and Space Environments, Ed. Springer, ISBN: 978-3-540-21193-8, 2008.

Pope, R. M. and Fry, E. S.: Absorption spectrum (380-700 nm) of pure water. II. Integrating cavity measurements, Appl. Opt., 36, 8710-8723, 1997.

Richter, A. and Wagner, T.: Diffuser plate spectral structures and their influence on GOME slant columns, Technical note, available online at: http://www.iup.uni-bremen.de/gome/data/ diffuser_gome.pdf, 2001.

Richter, A. and Burrows, J. P.: Retrieval of Tropospheric $\mathrm{NO}_{2}$ from GOME Measurements, Adv. Space Res., 29(11), 1673-1683, 2002.

Rodgers, C. D.: Inverse Methods for Atmospheric Sounding, Theory and Practice, World Scientific Publishing, Singapore, 2000.

Rothman, L. S., Jacquemart, D., Barbe, A., Chris Benner, D., Birk, M., Brown, L. R., Carleer, M. R., Chackerian Jr., C., Chance, K., Coudert, L. H., Dana, V., Devi, V. M., Flaud, J.-M., Gamache, 
R. R., Goldman, A., Hartmann, J.-M., Jucks, K. W., Maki, A. G., Mandin, J.-Y., Massie, S. T., Orphal, J., Perrin, A., Rinsland, C. P., Smith, M. A. H., Tennyson, J., Tolchenov, R. N., Toth, R. A., Vander Auwera, J., Varanasi, P., and Wagner, G.: The HITRAN 2004 molecular spectroscopic database, J. Quant. Spectrosc. Radiat. Transfer, 96, 139-204, 2005.

Saunders, S. M., Jenkin, M. E., Derwent, R. G., and Pilling, M. J.: Protocol for the development of the Master Chemical Mechanism, MCM v3 (Part A): tropospheric degradation of nonaromatic volatile organic compounds, Atmos. Chem. Phys., 3, 161-180, doi:10.5194/acp-3-161-2003, 2003.

Siddans, R., Latter, B. G., Kerridge, B. J., Smeets, J., Otter, G., and Slijkhuis, S.: Analysis of GOME-2, Slit function Measurements Final Report, Eumetsat Contract No. EUM/CO/04/1298/RM, 2006.

Sinreich, R., Coburn, S., Dix, B., and Volkamer, R.: Ship-based detection of glyoxal over the remote tropical Pacific Ocean, Atmos. Chem. Phys., 10, 11359-11371, doi:10.5194/acp-1011359-2010, 2010.

Smith, R. C. and Mobley, C. D.: Underwater Light, in: Photobiology: the science of life and light, 2nd Ed., Björn L.O., Springer, New York, USA, 131-138, doi:10.1007/978-0-387-72655-7_7, 2007.

Spurr, R.: LIDORT and VLIDORT: Linearized pseudo-spherical scalar and vector discrete ordinate radiative transfer models for use in remote sensing retrieval problems, in: Light Scattering Reviews, edited by: Kokhanovsky, A., Springer, 3, 229-275, 2008.

Stavrakou, T., Müller, J.-F., De Smedt, I., Van Roozendael, M., van der Werf, G. R., Giglio, L., and Guenther, A.: Evaluating the performance of pyrogenic and biogenic emission inventories against one decade of space-based formaldehyde columns, Atmos. Chem. Phys., 9, 1037-1060, doi:10.5194/acp-9-1037-2009, 2009a.

Stavrakou, T., Müller, J.-F., De Smedt, I., Van Roozendael, M., Kanakidou, M., Vrekoussis, M., Wittrock, F., Richter, A., and Burrows, J. P.: The continental source of glyoxal estimated by the synergistic use of spaceborne measurements and inverse modelling, Atmos. Chem. Phys., 9, 8431-8446, doi:10.5194/acp-9-8431-2009, 2009b.

Theys, N., Van Roozendael, M., Hendrick, F., Fayt, C., Hermans, C., Baray, J.-L., Goutail, F., Pommereau, J.-P., and De Mazière, M.: Retrieval of stratospheric and tropospheric BrO columns from multi-axis DOAS measurements at Reunion Island $\left(21^{\circ} \mathrm{S}\right.$, $56^{\circ}$ E), Atmos. Chem. Phys., 7, 4733-4749, doi:10.5194/acp-74733-2007, 2007.

van der Werf, G. R., Randerson, J. T., Giglio, L., Collatz, G. J., Mu, M., Kasibhatla, P. S., Morton, D. C., DeFries, R. S., Jin, Y., and van Leeuwen, T. T.: Global fire emissions and the contribution of deforestation, savanna, forest, agricultural, and peat fires (19972009), Atmos. Chem. Phys., 10, 11707-11735, doi:10.5194/acp10-11707-2010, 2010.

Van Roozendael, M., Loyola, D., Spurr, R., Balis, D., Lambert, J.-C., Livschitz, Y., Valks, P., Ruppert, T., Kenter, P., Fayt, C., and Zehner, C.: Ten years of GOME/ERS-2 total ozone data - The new GOME data processor (GDP) version 4: 1. Algorithm description, J. Geophys. Res., 111, D14311, doi:10.1029/2005JD006375, 2006.
Vandaele A.-C., Hermans, C., Simon, P. C., Carleer, M., Colin, R., Fally, S., Mérienne, M. F., Jenouvrier, A., and Coquart, B.: Measurements of the $\mathrm{NO}_{2}$ absorption cross-section from $42000 \mathrm{~cm}^{-1}$ to $10000 \mathrm{~cm}^{-1}(238-1000 \mathrm{~nm})$ at $220 \mathrm{~K}$ and 294 K, J. Quant. Spectrosc. Radiat. Transfer, 59, 171-184, 1998.

Vasilkov, A. P., Joiner, J., Gleason, J., and Bhartia, P.: Ocean Raman scattering in satellite backscatter UV measurements, Geophys. Res. Lett., 29, 1833, doi:10.1029/2002GL014955, 2002.

Volkamer, R., Spietz, P., Burrows, J., and Platt, U.: High-resolution absorption cross-section of glyoxal in the UV-vis and IR spectral ranges, J. Photochem. Photobiol. A: Chemistry, 172(1), 35-46, 2005 a.

Volkamer, R., Molina, L. T., Molina, M. J., Shirley, T., and Brune, W. H.: DOAS measurement of glyoxal as an indicator for fast VOC chemistry in urban air, Geophys. Res. Lett., 32, L08806, doi:10.1029/2005GL022616, 2005b.

Volkamer, R., Coburn, S. C., Dix, B. K., and Sinreich, R.: The Eastern Pacific Ocean is a source for short lived atmospheric gases: Glyoxal and iodine oxide, CLIVAR Exchanges, 15, 30-33, 2010.

Vrekoussis, M., Wittrock, F., Richter, A., and Burrows, J. P.: Temporal and spatial variability of glyoxal as observed from space, Atmos. Chem. Phys., 9, 4485-4504, doi:10.5194/acp-9-44852009, 2009.

Vrekoussis, M., Wittrock, F., Richter, A., and Burrows, J. P.: GOME-2 observations of oxygenated VOCs: what can we learn from the ratio glyoxal to formaldehyde on a global scale?, Atmos. Chem. Phys., 10, 10145-10160, doi:10.5194/acp-1010145-2010, 2010.

Wang, P., Stammes, P., van der A, R., Pinardi, G., and van Roozendael, M.: FRESCO+: an improved O2 A-band cloud retrieval algorithm for tropospheric trace gas retrievals, Atmos. Chem. Phys., 8, 6565-6576, doi:10.5194/acp-8-6565-2008, 2008.

Warneke, C., de Gouw, J. A., Del Negro, L., Brioude, J., McKeen, S., Stark, H., Kuster, W. C., Goldan, P. D., Trainer, M., Fehsenfeld, F. C., Wiedinmyer, C., Guenther, A. B., Hansel, A., Wisthaler, A., Atlas, E., Holloway, J. S., Ryerson, T. B., Peischl, J., Huey, L. G., and Case Hanks A. T.: Biogenic emission measurement and inventories determination of biogenic emissions in the eastern United States and Texas and comparison with biogenic emission inventories, J. Geophys. Res., 115, D00F18, doi:10.1029/2009JD012445, 2010.

Wittrock F., Richter, A., Oetjen, H., Burrows, J. P., Kanakidou, M., Myriokefalitakis, S., Volkamer, R., Beirle, S., Platt, U., and Wagner, T.: Simultaneous global observations of glyoxal and formaldehyde from space, Geophys. Res. Lett., 33, L16804, doi:10.1029/2006GL026310, 2006. 